\title{
Isolation of Salmonella Typhimurium from pigeons (Columba livia) in Greater Guwahati, its histopathological impact and antibiogram
}

\author{
Pankaj Dutta • Manoj Borah • Ratul Sarmah • Rakhi Gangil
}

Received: 7 August 2012 / Accepted: 13 September 2012 / Published online: 23 September 2012

(C) Springer-Verlag London 2012

\section{Introduction}

World over pigeons are mainly consumed as food and also maintained as cage birds. In Belgium and England, pigeons are reared scientifically as done for poultry. A variable susceptibility of the birds to bacterial infections and other diseases, including Salmonellosis, has been periodically documented from different parts of the world. Salmonellosis has been documented as the most prevalent disease of aviaries as well as in racing pigeons (Granville 1973). Occurrence of Salmonella Typhimurium was also reported to be predominant among the isolated Salmonellae (Dominici et al. 1976).

The present study was conducted to isolate and identify the serotypes of Salmonella spp. in diarrhoeic faecal samples and/or from fresh carcasses of pigeon. The associated gross and histopathological lesions and antimicrobial susceptibility were also documented.

P. Dutta $(\bowtie) \cdot$ R. Gangil

Department of Microbiology, Apollo College of Veterinary

Medicine,

Jaipur, Rajasthan, India

e-mail: drpankajdutta@yahoo.co.in

\section{Borah}

Department of Pathology, Apollo College of Veterinary Medicine, Jaipur, Rajasthan, India

R. Sarmah

Department of Microbiology, College of Veterinary Science,

Khanapara, India

\section{Materials and methods}

Fifty fresh diarrhoeic faecal samples and 100 fresh tissue samples from the lungs, liver, intestine, heart, spleen and kidney were collected from fresh pigeon carcasses in a sterile vial and brought to the laboratory. One gram of faecal or minced tissue sample was aseptically transferred into a sterile tube containing $10 \mathrm{ml}$ of Tetrathionate Broth and/or Rappaport Vassiliadis medium. The tubes were aerobically incubated at $42{ }^{\circ} \mathrm{C}$ for $24 \mathrm{~h}$, and then a loopful of broth culture was streaked onto Brilliant Green Agar plates and incubated aerobically at $37{ }^{\circ} \mathrm{C}$ for $24 \mathrm{~h}$, and suspected pinkish colonies were further inoculated onto Mac Conkey's lactose agar plates. The plates were incubated aerobically at $37^{\circ} \mathrm{C}$ for $24 \mathrm{~h}$ for isolation of the pathogen. Representative (lactose non-fermenting pale) colonies suspected to be Salmonella were obtained in pure culture on nutrient agar slants by conventional method, and the pathogen was identified as per the method described by Edward and Ewing (1972). The isolates were referred to the National Salmonella and Escherichia Centre, Central Research Institute, Kasauli (HP), India, for serotyping.

In vitro antibiotic sensitivity of the isolates was assessed using disc diffusion method (Bauer et al. 1966) using disc coated with 15 antibacterial drugs (Hi-Media), namely, ampicillin $10 \mu \mathrm{g}$, cephalexin $30 \mu \mathrm{g}$, cephotaxime $30 \mu \mathrm{g}$, chloramphenicol $30 \mu \mathrm{g}$, ciprofloxacin $10 \mu \mathrm{g}$, colistin $10 \mu \mathrm{g}$, cotrimoxazole $25 \mu \mathrm{g}$, furazolidone $50 \mu \mathrm{g}$, gentamicin $10 \mu \mathrm{g}$, nalidixic acid $30 \mu \mathrm{g}$, nitrofurantoin $300 \mu \mathrm{g}$, norfloxacin $10 \mu \mathrm{g}$, oxytetracycline $30 \mu \mathrm{g}$, streptomycin $10 \mu \mathrm{g}$ and tetracycline $30 \mu \mathrm{g}$. 


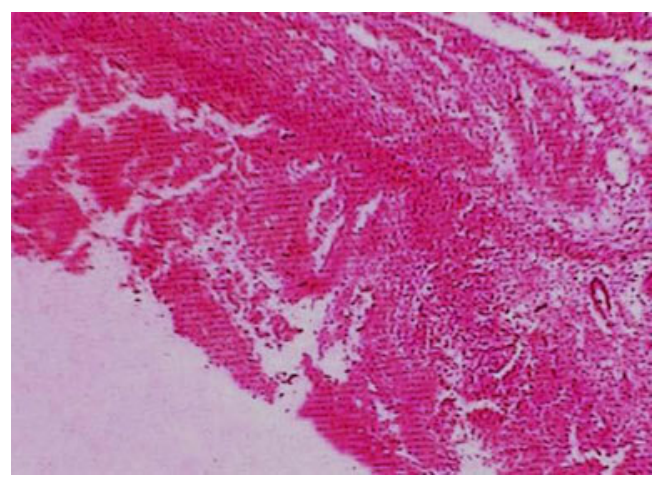

Fig. 1 Section of small intestine showed severe congestions with heterophilic and few mononuclear infiltrations. H \& E × 100

Tissue samples with gross visible lesions were preserved in $10 \%$ formalin and processed for histopathological investigations using standard protocol (Luna 1968). The paraffinembedded tissues were cut into sections of 4- to 5- $\mu$ thickness and stained with haematoxylin and eosin (H \& E) stain. Microscopic lesions in different organs were recorded.

\section{Results and discussion}

Out of 150 samples screened for Salmonella organisms from pigeons, 12 (8\%) Salmonella isolates could be recovered. All the strains were identified as Salmonella Typhimurium with antigenic structure 4, 5, I, 1, 2.

Gross lesions comprised of enteritis in $50 \%$ cases followed by hepatic congestion and necrosis $(25 \%)$ and pericarditis along with congestion of the spleen and kidneys (12.5\%). Congestion of the lungs (12.5\%) was also recorded in $12.5 \%$ cases. Histopathological investigation revealed intestinal congestion which extended into lamina propria and tunica muscularis (Fig. 1). There was infiltration of heterophils and few mononuclear cells with focal necrosis

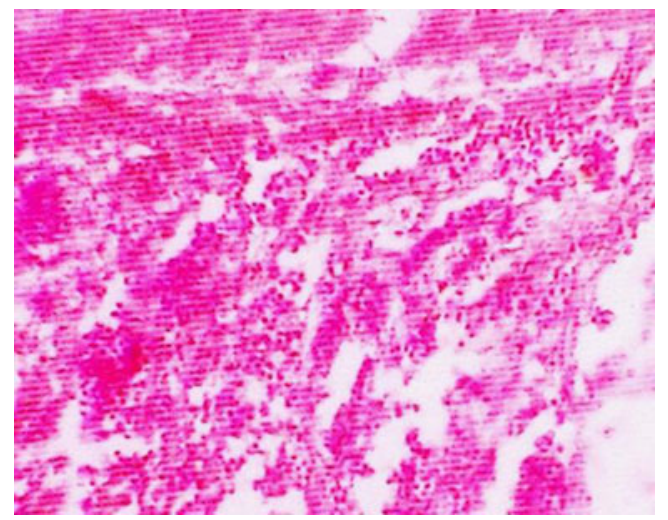

Fig. 2 Section of small intestine showed severe congestions with heterophilic and few mononuclear infiltrations. $\mathrm{H} \& \mathrm{E} \times 400$

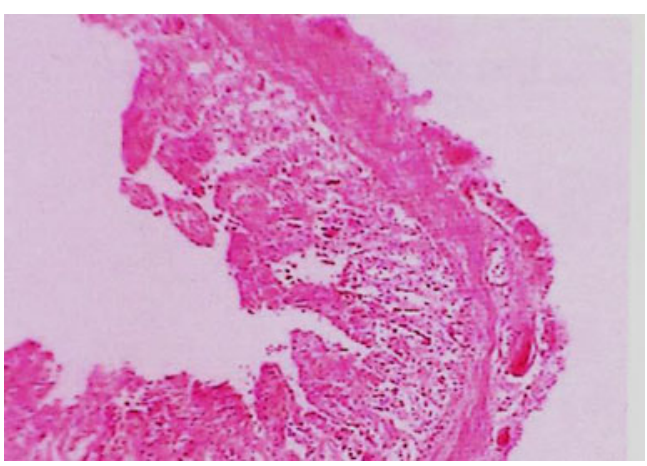

Fig. 3 Section of intestine showed severe necrosis followed by sloughing mucosa from the surface. $\mathrm{H} \& \mathrm{E} \times 100$

(Fig. 2). Sloughing of the intestinal mucosal layer was evident (Fig. 3). Further, the liver showed sinusoidal congestion and individualization of hepatocytes (Fig. 4) with various degrees of cellular degeneration and necrosis (Fig. 5). Congestion and haemorrhages in the lungs were noticed. Kidney revealed congestion and focal degeneration of tubular epithelial cells. Epicardium showed focal congestion. There was presence of severe congestion, haemorrhage and haemosiderosis on the spleen. Similar histopathological changes were earlier described and documented in poultry (Saikia 1984) and in pigeons (Phangcho 2001). Suganuma (1960) observed endothelial cell proliferative foci on the liver, focal necrosis of the myocardium, catarrhal enteritis and interstitial infiltration of lymphocytes in salmonellosis of chicks, adult hens and rosters.

In vitro antibiotic sensitivity of the isolates (Table 1) revealed $100 \%$ sensitivity towards ciprofloxacin followed by gentamicin, norfloxacin and chloramphenicol $(91.67 \%$ each), co-trimoxazole $(75.00 \%)$, cephalexin $(66.67 \%)$ and cephotaxime $(58.33 \%)$. The strains showed lower sensitivity to tetracycline and nitrofurantoin $(8.33 \%$ each) followed by oxytetracycline, streptomycin, furazolidone (16.67\%

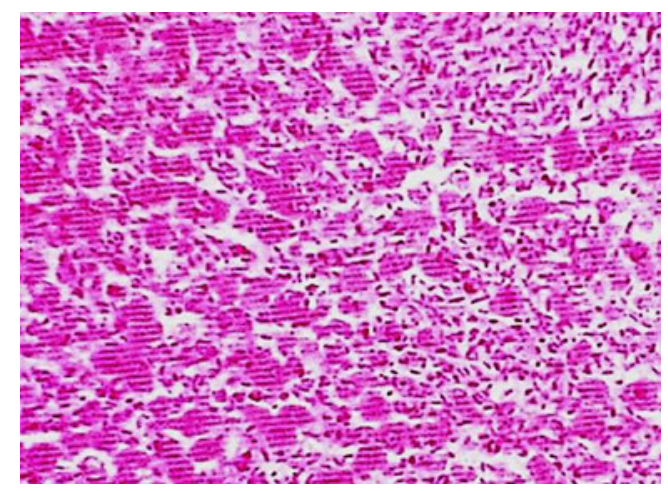

Fig. 4 Section of the liver showed sinusoidal congestion, individualization of hepatocytes. $\mathrm{H} \& \mathrm{E} \times 400$ 


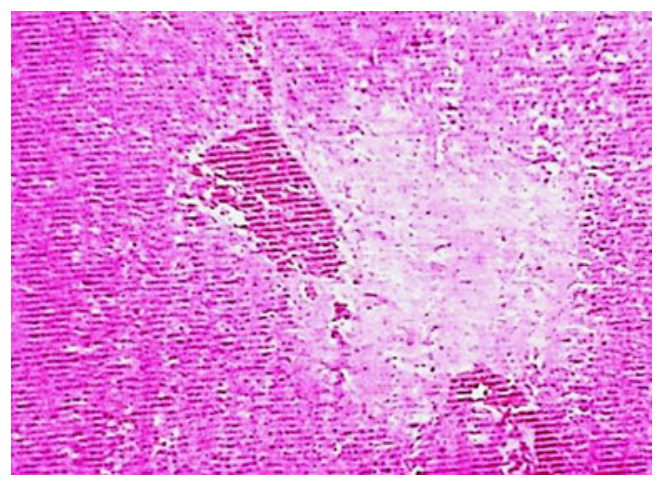

Fig. 5 Section of the liver showed various degrees of nuclear degeneration and hepatic necrosis. $\mathrm{H} \& \mathrm{E} \times 100$

each) and colistin (33.33\%). None of the Salmonella isolates were sensitive to ampicillin. Jha et al. (1994) showed that ciprofloxacin, gentamicin, nalidixic acid, nitrofurantoin and ampicillin were highly effective against Salmonella isolated in chicken. However, in the present study, ampicillin and nitrofurantoin were found less effective against Salmonella. Asagi et al. (1976) recorded sensitivity of Salmonella isolates from pigeons to tetracycline, streptomycin and kanamycin, but in the present study, streptomycin and tetracycline were found to be least effective on Salmonella. Cicek and Kovarik (1994) recorded the resistance of Salmonella isolated from poultry against ampicillin, streptomycin and colistin. Besides, Pathan et al. (1998) observed the resistance of salmonellae recovered from poultry and pigs to tetracycline, oxytetracycline, streptomycin and trimethoprim. Similarly, Sharma and Joshi (1992) also recorded high sensitivity of salmonellae to gentamicin. Similar patterns of sensitivity of Salmonella isolated from broilers to ciprofloxacin, gentamicin and amikacin was recorded earlier by Swaminathan (2001). He also observed high degree of resistance to ampicillin, oxytetracycline, co-trimoxazole, chloramphenicol, norfloxacin and enrofloxacin. However, in the present study, resistance to these drugs was not seen except to ampicillin and oxytetracycline.

Salmonella Typhimurium strains in the present study have shown higher resistance towards ampicillin, tetracycline and nitrofurantoin. This could be attributed to many reasons like indiscriminate use of these antibiotics without prescription, lack of proper veterinary consultation, not performing an antibiogram when the situation warrants, improper treatment regimens, etc. The routine practice of giving antimicrobial agents to domestic livestock as a means of preventing and treating diseases, as well as promoting growth, is an important factor in the emergence of antibiotic-resistant bacteria that are subsequently transferred to humans through the food chain. Most infections with antimicrobial-resistant Salmonella in human are acquired by eating contaminated foods of animal origin (Andoni 1982; Avril et al. 1988).

Knowing the resistance of Salmonella Typhimurium strains towards different antimicrobial agents helps the veterinarians to offer a better and more effective treatment to livestock diagnosed with salmonellosis by using the indispensable antibiotic and replacing the resistant antibiotics with new ones. Thus, the present investigation indicated the prevalence of important multidrug-resistant pathogens like Salmonella Typhimurium in pigeons, which is of zoonotic importance.
Table 1 Antibiogram of Salmonella Typhimurium isolates

\begin{tabular}{llllllll}
\hline Sl no. & Antibiotic & Not tested & Sensitive & Percent & Not tested & Resistant & Percent \\
\hline 1 & Ampicillin & 12 & 0 & 0 & 12 & 12 & 100 \\
2 & Chloramphenicol & 12 & 11 & 91.67 & 12 & 1 & 8.33 \\
3 & Cephalexin & 12 & 8 & 66.67 & 12 & 4 & 33.33 \\
4 & Cephotaxime & 12 & 7 & 58.33 & 12 & 5 & 41.67 \\
5 & Ciprofloxacin & 12 & 12 & 100 & 12 & 0 & 0 \\
6 & Colistin & 12 & 4 & 33.33 & 12 & 8 & 66.67 \\
7 & Co-trimoxazole & 12 & 9 & 75 & 12 & 3 & 25 \\
8 & Furazolidone & 12 & 2 & 16.67 & 12 & 10 & 83.33 \\
9 & Gentamicin & 12 & 11 & 91.67 & 12 & 1 & 8.33 \\
10 & Nalidixic acid & 12 & 6 & 50 & 12 & 6 & 50 \\
11 & Nitrofurantoin & 12 & 1 & 8.33 & 12 & 11 & 91.67 \\
12 & Norfloxacin & 12 & 11 & 91.67 & 12 & 1 & 8.33 \\
13 & Oxytetracycline & 12 & 2 & 16.67 & 12 & 10 & 83.33 \\
14 & Streptomycin & 12 & 2 & 16.67 & 12 & 10 & 83.33 \\
15 & Tetracycline & 12 & 1 & 8.33 & 12 & 11 & 91.67 \\
\hline
\end{tabular}


Acknowledgments The authors are thankful to the Director of the National Salmonella and Escherichia Centre, Central Research Institute, Kasauli (HP), India, for serotyping the Salmonella isolates.

\section{References}

Andoni R (1982) Diagnoza Bakterologjike elnfeksioneve ne Klinike. D. A. Sh. Tirana. (in Albanian)

Asagi M, Oka C, Sato G (1976) Isolation of Salmonella Typhimurium var. copenhagen from crows in the city of Otaru. Jpn J Vet Sci 38 (5):521-522

Avril JL, Dabernat H, Denis F, Monteil H (1988) Bacteriologie Clinique. Ellipses, Paris

Bauer AW, Kirby WM, Sherris JS, Turck M (1966) Antibiotic susceptibility testing by a standardized single disk method. Am J Clin Pathol 45(4):493-496

Cicek A, Kovarik K (1994) Antibiotic resistance in Salmonella Typhimurium Enteritidis strains isolated from poultry in Czech Republic 1991-1992. Vet Med 39(9):551-557

Dominici S, Gialletti L, Morozzi A, Tiecco GC (1976) Salmonellosis of animals in Umbria. Giene-e-Sanita Pubblica 32(11/12):296-310

Edward PR, Ewing WH (1972) Identification of Enterobacteriaceae. 3rd Burgess Publishing Company, Minneapolis
Granville J (1973) Clinical features of the principal diseases of pigeons. Ann Med Vet 117(5):289-324

Jha VC, Thakur RP, Chand TK, Tadav JN (1994) Prevalence of salmonellosis in chickens in Eastern Nepal. Vet Rec Kathmandu 9(1):4-6

Luna LG (1968) Manual of histologic staining methods of the Armed Forces Institute of Pathology, 3rd edn. McGraw-Hill, New York

Pathan NP, Tantic HT, Satuwong I (1998) Antimicrobial drug resistance of Salmonella spp. and E. coli in food animals. J Thai Vet Med Assoc 49(1/3):11-23

Phangcho CV (2001) Etiopathological studies on the prevailing diseases of domestic pigeons (Columba livia). $\mathrm{PhD}$ thesis, Assam Agric. Univ. Guwahati, India

Saikia GK (1984) Studies on some aspects of Salmonella infection in poultry and its products. M.V.Sc thesis, Assam Agric. Univ., Guwahati, India

Sharma DK, Joshi DV (1992) Incidence, antibiogram and public health significance of Salmonella isolated from abattoir's equipment and handlers. Indian J Comp Microbiol Immunol Infect Dis 19(1/ 2):48-51

Suganuma Y (1960) Histopathological studies on serositis of pullorum disease. Jpn J Vet Sci 22:175-182

Swaminathan TR (2001) Salmonellosis of broilers in Tamilnadu. Indian J Anim Sci 71(11):1016-1017 